\title{
WOMEN RELIGIOUS AND EPISTOLARY EXCHANGE IN THE \\ CARMELITE REFORM. THE DISCIPLES OF TERESA DE ÁVILA
}

\section{BÁRBARA MUJICA}

\author{
Ámsterdam, 2020, Amsterdam University Press, 327 páginas
}

ISBN: 978-94-6372-343-5

En las últimas décadas ha tenido lugar un intenso proceso de revisión e reinterpretación de la historiografía tradicional en clave de Género, generando así una corriente de estudios fundamental y necesaria, que aglutina a investigadoras e investigadores de todas las disciplinas humanísticas.

La permanente y crítica relectura del papel asignado a las mujeres a lo largo de la historia ha cuestionado las bases tanto conceptuales como metodológicas empleadas, claramente parciales y subjetivas, y ha puesto sobre la mesa el desconocimiento del múltiple rol ejercido históricamente por las mujeres, que en la mayoría de los casos permanecía silenciado o invisibilizado.

El libro Women Religious and Epistolary Exchange in the Carmelite Reform. The Disciples of Teresa de Ávila, editado en 2020 por la Amsterdam University Press, se suma a este movimiento, pues se enmarca en una línea de publicaciones dedicada a la difusión de investigaciones interdisciplinares, de enfoque global, sobre mujeres, género y sexualidad entre la Baja Edad Media y los albores de la Edad Moderna.

Su autora, la Dra. Bárbara Mujica, es Profesora Emérita en la Universidad de Georgetown (Washington D.C.) y especialista en Literatura Española de la temprana Edad Moderna. Ensayista, novelista, crítica e investigadora, ha centrado este último interés en la escritura femenina, realizando una importante contribución sobre la actividad de las mujeres en el ámbito religioso. Concretamente, en la presente obra analiza el papel desempeñado por las seguidoras de Teresa de Ávila en la Reforma de la Orden Carmelita a través de sus cartas.

Cabe mencionar cómo la correspondencia en las casas femeninas hunde su tradición en la Edad Media, formando parte esencial de las gestiones de la vida monástica, y constituyendo el medio de comunicación de las propias religiosas, quienes en muchos casos accedían a esta formación en el contexto conventual. No obstante, esta actividad significaba para la clausura un contacto extramuros, lo cual en ocasiones fue interpretado por las autoridades eclesiásticas como una violación de la norma, por lo que estas prácticas codificadas fueron reguladas de forma desigual en distintos períodos. 
Como la propia Mujica explica en el prólogo, esta publicación tiene como punto de partida Teresa de Avila, Lettered Woman, obra previa donde la autora realizó un pormenorizado estudio de la producción epistolar de la religiosa, prolífica escritora y fundadora, quien en sus cartas ofrece una valiosa información para conocer el proceso de Reforma Carmelita a través de la experiencia femenina. Será aquí donde surgirá la necesidad de completar dicha visión y sumar el papel otras mujeres en el seno de esta orden, analizando la también valiosa producción escrita de las sucesoras de Teresa durante en el siglo XVII.

Se esboza así, el retrato de una generación de mujeres que, siguiendo la estela de la primera reformadora, marcaron tendencia y renovaron la espiritualidad femenina oponiéndose a la jerarquía eclesiástica, y llevando a cabo la expansión territorial internacional de la nueva Orden de Carmelitas Descalzas, una misión verdaderamente revolucionaria en este contexto.

A pesar de que este período ha resultado el epicentro de múltiples estudios acerca de la mencionada reorganización eclesiástica, hasta el momento la visión puramente androcéntrica ha definido el conocimiento sobre este asunto. Es por ello que la aportación principal de Mujica es analizar y trasladar la información que de primera mano revelan las fuentes femeninas, concretamente la documentación epistolar de tres de las discípulas más cercanas a la aludida mística: María de San José, Ana de Jesús y Ana de San Bartolomé.

Generalmente, la producción escrita de estas religiosas será amplia y variada a lo largo de sus vidas, comprendiendo tanto tratados, como memorias espirituales, poesía y cartas. Sus biografías y su actividad religiosa como prioras quedarán descritas a través de estos textos, articulándose la estructura del presente libro en tres partes diferenciadas, centradas en cada una de las religiosas. A ello le precede una introducción de la autora, donde además de dar contexto a los bloques subsiguientes, integra un interesante apartado de fuentes consultadas.

El cuerpo de la obra ofrece así los testimonios vitales de las seguidoras, algunas en comunicación epistolar directa con la propia Teresa de Jesús en vida. En sus escritos exponen tanto cuestiones relativas a la gestión de las fundaciones, sus intereses personales, así como problemáticas inherentes a la convivencia y a la vida conventual en su vertiente doméstica y ritual. Asimismo, narran por separado los condicionantes y desafíos que el proceso de reforma y sus circunstancias les imponen: sus tortuosos viajes a Portugal (todavía territorio español), Francia y Países Bajos respectivamente, y su lucha común frente a la hostilidad que deriva de las nuevas tierras y sus constantes enfrentamientos a la jerarquía eclesiástica, reticente a la amenaza que la nueva orden supone. 
Por último, se incluye un breve apunte sobre la correspondencia de Catalina de Cristo, otra religiosa que, siendo cercana a Ana de San Bartolomé, ofrece en sus escritos la visión y experiencia de su permanencia en España en ausencia de estas hermanas viajeras.

Para finalizar, un capítulo de conclusiones, esclarecedor al hilo de los testimonios ofrecidos; un breve apartado biográfico sobre la autora de la obra, y, un índice temático cuya consulta resulta de gran utilidad para la búsqueda de referencias concretas en el libro.

En definitiva, esta publicación se suma a la ardua tarea de reescritura de la Historia bajo una perspectiva de Género, rescatando la voz femenina en el proceso de Reforma Carmelita, compilando así las experiencias de las religiosas en primera persona y analizando los pormenores de la correspondencia de estas mujeres: una herramienta que más allá de su papel en las relaciones sociales e institucionales, constituyó una sutil estrategia de comunicación política, prueba de la lucha reformista, y del liderazgo femenino.

María del Castillo García Romero

Universidad de Sevilla 